\title{
水稻机械精量有序抛秧栽培的产量形成和生长发育特征研究
}

\author{
王慰亲 ${ }^{1}$ 唐启源 ${ }^{1, *}$ 陈元伟 ${ }^{1}$ 贾 巍 $^{1}$ 罗友谊 $^{1}$ 王小升 $^{1}$ 郑华斌 ${ }^{1}$ \\ 熊娇军 ${ }^{2}$
}

${ }^{1}$ 湖南农业大学农学院, 湖南长沙 $410128 ;^{2}$ 大通湖区宏硕生态农业农机合作社, 湖南益阳 413207

摘 要: 水稻机械精量有序抛种栽培是指通过有序抛积机进行水稻分行分寛有序抛栽的机械化种植方式, 解决了传 统抛种栽培田间种植无序和作业效率低等问题。本研究以手插种和手抛积模式作为对照, 通过 2018一-2019 年的比较 试验系统探究了精量有序机抛种模式下水稻产量形成的特点及生长发育特性。研究结果表明, 精量有序机抛秧较手 插种增产 $22.4 \%$ 28.3\%, 较手抛秧增产 $2.8 \%$ $8.9 \%$ 。生长发育特性方面, 精量有序机抛秧群体通风性好, 生育后期的 干物质同化积累能力强, 花后干物质积累量较手插种和手抛秧分别增加 $52.8 \%$ 和 23.4\%; 叶片衰老较慢、库充实度高, 与手插积相比, 其单位面积有效穗数显著增加 20.9\% 64.2\%; 与手抛种相比, 结实率增加 3 5 个百分点, 进而促进其 高产。然而, 精量有序机抛栽培模式下抛积机及配套育种技术等方面还有待改进以进一步发挥高产潜能, 同时围绕精 量有序机抛秧技术的立苗缓青特征、分薛发生特性和根系生长特点等方面的研究还有待深入开展。

关键词：水稻; 有序机抛种; 产量; 生长发育特性

\section{Evaluation of orderly mechanical seedling-broadcasting on yield formation and growth characteristics of rice}

\author{
WANG Wei-Qin ${ }^{1}$, TANG Qi-Yuan ${ }^{1,}{ }^{*}$, CHEN Yuan-Wei ${ }^{1}$, JIA Wei ${ }^{1}$, LUO You-Yi ${ }^{1}$, WANG Xiao-Hui ${ }^{1}$, ZHENG \\ Hua-Bin $^{1}$, and XIONG Jiao-Jun ${ }^{2}$ \\ ${ }^{1}$ College of Agronomy, Hunan Agricultural University, Changsha 410128, Hunan, China; ${ }^{2}$ The Corporation of Hongshuo Agriculture, Yiyang 413207, \\ Hunan, China
}

\begin{abstract}
Orderly mechanical seedling-broadcasting refers to the rice establishment methods that throw-transplanted the rice seedlings to the field in rows and lines by seedling broadcasting machine. Which are suggested to prominently increase the uniformity and efficiency of rice crops compared with manual seedling broadcasting. The present study was carried out to compare the differences between orderly mechanical seedling-broadcasting, manual transplanting and manual seedling broadcasting regarding yield formation and growth characteristics of rice. The results suggested that the grain yield of rice under orderly mechanical seedling-broadcasting was increased compared with manual transplanting and manual seedling broadcasting by $22.4 \%-28.3 \%$ and $2.8 \%-8.9 \%$, respectively. On the aspect of growth traits, the orderly mechanical seedling-broadcasting was characterized as good ventilation, better assimilation ability of dry matter at late growth stages, delayed leaf senescence and high grain filling percentage, which increased the panicle numbers per square meter by $20.9 \%-64.2 \%$ compared with that of manual transplanting and increased the seed setting rate as compared with manual seedling-broadcasting. However, in order to further develop the potential of high yield, the techniques and planting machines of orderly mechanical seedling-broadcasting still need to be improved. In addition, the process of seedling recovery, tiller development and root growth traits of rice under orderly mechanical seedling-broadcasting should be explored in future studies.
\end{abstract}

Keywords: rice; orderly mechanical seedling-broadcasting; yield; growth characteristics

水稻是我国最重要的粮食作物之一, 我国人多＼cjkstart地少, 对粮食有着巨大的需求, 然而随着经济的发

\footnotetext{
本研究由国家现代农业产业技术体系建设专项(CARS-01-26)资助。

This study was supported by the Earmarked Fund for China Agriculture Research System (CARS-01-26).

*通信作者(Corresponding author): 唐启源, E-mail: cntqy@aliyun.com

第一作者联系方式: E-mail: wwqbrad@163.com

Received (收稿日期): 2020-05-12; Accepted (接受日期): 2020-11-13; Published online (网络出版日期): 2020-12-23.

URL: https://kns.cnki.net/kcms/detail/11.1809.S.20201223.0844.002.html
} 
展和城市化进程的加快，农村劳动力的迅速减少使 得传统人工栽插的种植方式不能满足当前水稻生产 的需求。为保证口粮安全，我国传统水稻生产方式 必须朝机械化、轻简化的方向转型。

抛种栽培是采用塑盘育苗或旱育苗, 育出根部 带土球(针)的种苗, 移栽时依靠带土球(针)种苗的自 身重力，通过人工或机械均匀的抛栽到田里的一种 轻简型栽培方式 ${ }^{[1]}$ 。和传统人工移栽相比，抛种栽培 大幅度地减轻了移栽过程中的劳动力投入。自 20 世 纪 80 年代以来, 我国对抛种栽培进行了大量的科学 研究和示范推广工作, 抛种种植面积迅速增加 ${ }^{[2-4]}$ 。

抛种栽培主要有手工抛栽和机械抛栽 2 种形式, 而我国目前以手工抛栽为主。前人围绕手抛种稻的 生长发育特性和产量形成特点进行了大量研究, 发 现手抛种的生长特点主要包括移栽后缓苗期短、植 伤轻, 根系发达, 前期分䔉多, 单位面积穗数和有 效颖花数多 ${ }^{[4-5]}$ 。然而, 和手插种稻相比, 手抛种的 最大特点是种植无序, 不成行成株, 田间通风透光 条件差, 湿度大, 导致下部叶片衰老腐烂、病虫害滋 生严重、易倒伏等 ${ }^{[6-8]}$ 。同时, 手抛种移栽作业效率 低, 在当前农村劳动力严重缺乏的现状和土地流转 承包、水稻规模化生产的发展趋势下, 传统手抛种 正朝机抛种发展转型。

国内外围绕抛种机械及配套栽培技术开展了多 年研究 ${ }^{[9]}$, 目前我国应用的抛种机主要有无序抛种 机和有序抛种机 2 种类型 $[10]$ 。其中无序抛种机虽然 作业效率高, 省工省成本, 但是其抛种无序, 种苗 在田间分布杂乱, 田间通风透光差, 产量优势难以 发挥 ${ }^{[11]}$ 。为了解决无序抛种存在的问题, 前人进行 了播栽、摆栽等有序方式的尝试研究 ${ }^{[12-13]}$; 湖南巽 地农机于 2018 年发明生产了国内第一台由井关机 头牵引的高速有序抛种机, 现由湖南中联重机有限 公司收购并加以完善, 可实现水稻分行分筧有序抛 栽, 基本解决了传统人工抛种或机抛种种植无序的 问题, 同时可满足不同稻作季别、不同品种的种植 要求, 是未来发展的重要方向 ${ }^{[14]}$ 。本课题组近几年 围绕水稻精量有序机抛栽培技术开展了相关研究并 在湖南多地推广示范, 发现和传统插种或手抛种相 比，其增产效应明显。然而目前围绕精量有序机抛 栽培的研究较少, 其生长发育特性和高产形成特点 还鲜有研究报道。

本研究以国内第一台由井关机头牵引的高速有 序抛积机(2ZP-13)实现水稻有序抛种, 通过比较其
与手抛种和手插种在产量形成、干物质积累转运、 分藮发生等方面的差异, 探究精量有序机抛栽培水 稻的产量形成特点和生长发育特性, 以期为水稻机 械精量有序栽培技术的研发应用提供理论依据。

\section{1 材料与方法}

\section{1 供试材料与试验地点}

试验于 2018-2019年在湖南省益阳市大通湖区 千山红镇 $\left(112^{\circ} 15^{\prime} 28^{\prime \prime} \mathrm{E}, 29^{\circ} 01^{\prime} 19^{\prime \prime} \mathrm{N}\right)$ 进行。土壤成土 母质系河湖沉积物, 土壤基础地力情况为 $\mathrm{pH} 8.02$, 有机质 $27.9 \mathrm{~g} \mathrm{~kg}^{-1}$, 碱解氮 $117.37 \mathrm{mg} \mathrm{kg}^{-1}$, 有效磷 $15.57 \mathrm{mg} \mathrm{kg}^{-1}$, 缓效钾 $335.3 \mathrm{mg} \mathrm{kg}^{-1}$, 速效钾 111.07 $\mathrm{mg} \mathrm{kg}^{-1}$ 。供试材料为黄华占 (常规籼稻)和角优 1538 (籼粳杂交稻)。

\section{2 试验设计}

试验采用裂区设计，主区处理为种植方式，分 别为手插种、手抛种和精量有序机抛种, 副区处理 为品种, 分别为黄华占和甬优 1538 。试验设 3 次重 复, 小区面积为 $81 \mathrm{~m}^{2}(9 \mathrm{~m} \times 9 \mathrm{~m})$, 小区之间做田埂 隔开并且覆膜, 防止小区间窝水窝肥。2018 年于 5 月 27 日播种, 6 月 15 日进行移栽, 2019 年于 5 月 27 日播种，6月 17 日进行移栽。手抛种和有序机抛种 分别用 353 孔塑料软盘和 416 孔专用种盘, 每孔 $3 \sim 5$ 粒, 泥浆湿润育种; 手插种采用传统湿润育种, 播 种量 $15 \mathrm{~kg} \mathrm{hm}^{-2}$, 每穴栽插 3 粒谷种苗。3 种种植方 式的移栽密度保持一致, 手插种行株距为 $20 \mathrm{~cm} \times$ $20 \mathrm{~cm}$; 精量有序机抛积行株距为 $25 \mathrm{~cm} \times 16 \mathrm{~cm}$, 手 抛种密度为 25 穴 $\mathrm{m}^{-2}$ 。试验各品种按照 $\mathrm{N}: \mathrm{P}_{2} \mathrm{O}_{5}$ ： $\mathrm{K}_{2} \mathrm{O}=1.0 ： 0.5 ： 1.0$ 的比例进行施肥，甬优 1538 施纯 $\mathrm{N} 240 \mathrm{~kg} \mathrm{hm}^{-2} 、 \mathrm{P}_{2} \mathrm{O}_{5} 120 \mathrm{~kg} \mathrm{hm}^{-2} 、 \mathrm{~K}_{2} \mathrm{O} 240 \mathrm{~kg} \mathrm{hm}^{-2}$, 黄华占施纯 $\mathrm{N} 195 \mathrm{~kg} \mathrm{hm}^{-2} 、 \mathrm{P}_{2} \mathrm{O}_{5} 97.5 \mathrm{~kg} \mathrm{hm}^{-2} 、 \mathrm{~K}_{2} \mathrm{O}$ $195 \mathrm{~kg} \mathrm{hm}^{-2}$, 其中氮肥按基肥 $(50 \%) 、$ 分藍肥 $(20 \%)$ 和穗肥 (30\%)施用，磷肥全部用作基肥，钾肥按基 肥和穗肥各 $50 \%$ 施用。其他田间管理方式同当地高 产栽培习惯。

\section{3 测定指标}

1.3.1 产量与产量构成于成熟期, 按对角线取 样法，从小区中间选取代表性植株 5 丛调查有效穗 数(实粒数大于 5 粒的稻穗), 手工脱粒后用自来水分 离实粒和秕粒, 实粒称取 3 份 $30 \mathrm{~g}$, 秕粒称取 3 份 $3 \mathrm{~g}$, 计数后在 $70^{\circ} \mathrm{C}$ 下烘干至恒质量, 考察每穗粒 数、结实率和千粒重(恒质量), 茎秆和叶在 $80^{\circ} \mathrm{C}$ 下烘 干至恒重, 测定干物质量。成熟期总干物质量为样 
本茎秆和叶、实粒、秕粒和枝梗干质量之和。从每 小区中心收割 $5 \mathrm{~m}^{2}$ 用于测产, 含水量按粳稻 14\%、 籼稻 $13 \%$ 进行折算。

\subsection{2 干物质积累于分菜中期、幼穗分化期、} 抽穗期、齐穗后 $10 \mathrm{~d}(\mathrm{FL}+10 \mathrm{~d})$ 和收获期 $(\mathrm{PM})$ 取样, 每个小区取 6 穴, 然后剪去根, 按叶、茎+鞘、穗分开, 置于 $105^{\circ} \mathrm{C}$ 。恒温下杀青 $30 \mathrm{~min}, 80^{\circ} \mathrm{C}$ 鼓风干燥箱烘 干至恒重, 冷却至恒温后称重, 计算干物质重量

\subsection{3 分藥动态 于移栽返青后各处理定 0.25} $\mathrm{m}^{2}$ 面积秧苗, 调查基本苗, 每 $3 \mathrm{~d}$ 调查 1 次分藍数, 直至分葟数保持稳定下降后或到齐穗期为止。

\subsubsection{SPAD 值及株高 于分葟中期、幼穗分化} 期、齐穗期、齐穗后 $10 \mathrm{~d}$ 采用 SPAD 仪对每小区生 长均匀具有代表性的(除开边 3 行)水稻主茎的上三 叶进行相对叶绿素含量的测量, 每片叶子分别测叶 片上部、中部、下部 3 个位置, 得出平均值, 每个小
区测量 3 株。

1.3.5 风速和阵风速度为比较精量有序机抛秩 与手插秧、手抛秩的田间通风性差异, 于 2019 年 8 月 28 日 15 时至 8 月 29 日 15 时(齐穗期), 采用 HOBO datalogger 测定不同种植方式下水稻群体的风速和 阵风速度。测定群体风速时各品种在不同种植方式 下的株高、生物量等基础数据如表 1 所示。

\section{4 数据处理与分析}

采用Microsoft Excel对数据进行收集整理和作 图, 采用Statistix 8.0进行统计分析, SigmaPlot 10.0 作图。处理间的样本均值在最小差异显著法(LSD) 进行比较。

\section{2 结果与分析}

\section{1 生育期}

3 种种植方式的生育期差异较小(表 2)。2018 年

表 1 田间群体风速测定时各品种和种植方式的群体特征指标

Table 1 Growth characteristics of rice varieties and planting model with the measurement of wind speed

\begin{tabular}{|c|c|c|c|c|}
\hline 品种 & 种植方式 & 株高 & 地上部生物量 & 叶面积指数 \\
\hline Variety & Planting pattern & Plant height $(\mathrm{cm})$ & Above-ground biomass $\left(\mathrm{g} \mathrm{m}^{-2}\right)$ & Leaf area index \\
\hline 黄华占 & 手插秩 Manual transplanting & 104.2 & 863.5 & 4.13 \\
\hline \multirow[t]{2}{*}{ Huanghuazhan } & 手抛秩 Manual seedling-broadcasting & 109.7 & 1325.7 & 7.23 \\
\hline & 机抛秧 Mechanical seedling-broadcasting & 105.1 & 1172.8 & 6.88 \\
\hline 角优 1538 & 手插秩 Manual transplanting & 104.6 & 1042.4 & 4.32 \\
\hline \multirow[t]{2}{*}{ Yongyou 1538} & 手抛秩 Manual seedling-broadcasting & 105.4 & 1602.6 & 7.84 \\
\hline & 机拋秩 Mechanical seedling-broadcasting & 103.6 & 1248.1 & 7.26 \\
\hline
\end{tabular}

表 2 黄华占和角优 1538 在不同种植方式下的生育期表现

Table 2 Growth durations of Huanghuazhan and Yongyou 1538 under different rice establishment methods

\begin{tabular}{|c|c|c|c|c|c|c|c|}
\hline $\begin{array}{l}\text { 年份 } \\
\text { Year }\end{array}$ & $\begin{array}{c}\text { 品种 } \\
\text { Variety }\end{array}$ & & $\begin{array}{c}\text { 种植方式 } \\
\text { Establishment methods }\end{array}$ & $\begin{array}{c}\text { 播种-移栽 } \\
\text { Seeding- } \\
\text { Transplanting } \\
\text { (d) }\end{array}$ & $\begin{array}{c}\text { 移栽-齐穗 } \\
\text { Transplanting- } \\
\text { Heading } \\
\text { (d) }\end{array}$ & $\begin{array}{c}\text { 齐穗-成熟 } \\
\text { Heading- } \\
\text { Maturity } \\
\text { (d) }\end{array}$ & $\begin{array}{l}\text { 全生育期 } \\
\text { Growth } \\
\text { durations } \\
\text { (d) }\end{array}$ \\
\hline \multirow[t]{6}{*}{2018} & 黄华占 & 手插秧 & Manual transplanting & 20 & 65 & 38 & 123 \\
\hline & Huanghuazhan & 手抛秩 & Manual seedling-broadcasting & 20 & 65 & 36 & 121 \\
\hline & & 机抛秧 & Mechanical seedling-broadcasting & 20 & 65 & 36 & 121 \\
\hline & 角优 1538 & 手插秧 & Manual transplanting & 20 & 74 & 50 & 144 \\
\hline & Yongyou 1538 & 手抛秧 & Manual seedling-broadcasting & 20 & 73 & 49 & 142 \\
\hline & & 机抛秧 & Mechanical seedling-broadcasting & 20 & 73 & 49 & 142 \\
\hline \multirow[t]{6}{*}{2019} & 黄华占 & 手插秧 & Manual transplanting & 21 & 65 & 33 & 119 \\
\hline & Huanghuazhan & 手抛秧 & Manual seedling-broadcasting & 21 & 64 & 33 & 118 \\
\hline & & 机抛秧 & Mechanical seedling-broadcasting & 21 & 67 & 33 & 121 \\
\hline & 角优 1538 & 手插秧 & Manual transplanting & 21 & 67 & 50 & 138 \\
\hline & Yongyou 1538 & 手抛秩 & Manual seedling-broadcasting & 21 & 68 & 51 & 140 \\
\hline & & 机抛秧 & Mechanical seedling-broadcasting & 21 & 69 & 52 & 142 \\
\hline
\end{tabular}


黄华占和角优 1538 在精量有序机抛秧模式下的生 育期分别为 $121 \mathrm{~d}$ 和 $142 \mathrm{~d}$, 与手抛秩生育期一致, 且较手插秧生育期缩短 2 d。2019 年的生育期表现 与 2018 年存在一定差异。黄华占精量有序机抛秧的 生育期为 $121 \mathrm{~d}$, 较手插种和手抛秧分别延长 $2 \mathrm{~d}$ 和 $3 \mathrm{~d}$, 而角优 1538 精量有序抛秧的生育期与手插秧和 手抛秧相比分别延长了 $4 \mathrm{~d}$ 和 $2 \mathrm{~d}$ 。

\section{2 产量与产量构成}

黄华占和角优 1538 在不同种植方式下的产量如 图 1 所示, 2018 年黄华占在机械精量有序抛秧模式 下的产量为 $9.75 \mathrm{t} \mathrm{hm}^{-2}$, 较手插秧增产 $8.8 \%$, 但与

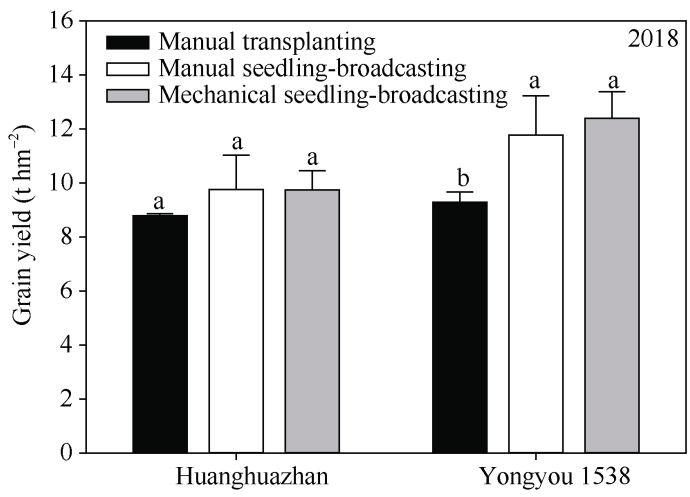

手抛秧产量无显著性差异。角优 1538 机械精量有序 抛秧在 3 种种植方式下的产量最高, 达 $12.39 \mathrm{t} \mathrm{hm}^{-2}$, 与手插秩和手抛种相比分别增加 $33.3 \%$ 和 $5.1 \%$ 。 2019 年精量有序机抛秧模式下的产量显著高于手插 秩和手抛秩, 其中黄华占机抛秧的产量为 $9.90 \mathrm{t} \mathrm{hm}^{-2}$, 较手插秧和手抛秩分别增产 $39.2 \%$ 和 $9.8 \%$, 而甬优 1538 机抛秧产量为 $12.23 \mathrm{t} \mathrm{hm}^{-2}$, 与手插种与手抛种 相比产量分别增加 $20.6 \%$ 和 $8.2 \%$ 。综合品种表现, 精 量有序机抛秧较手插秧增产 $22.4 \%$ 2 $8.3 \%$, 较手拋 秧增产 $2.8 \% \sim 8.9 \%$ 。分析产量构成因子(表 3)发现, 机械精量有序抛秧的单位面积有效穗数较手插秧增

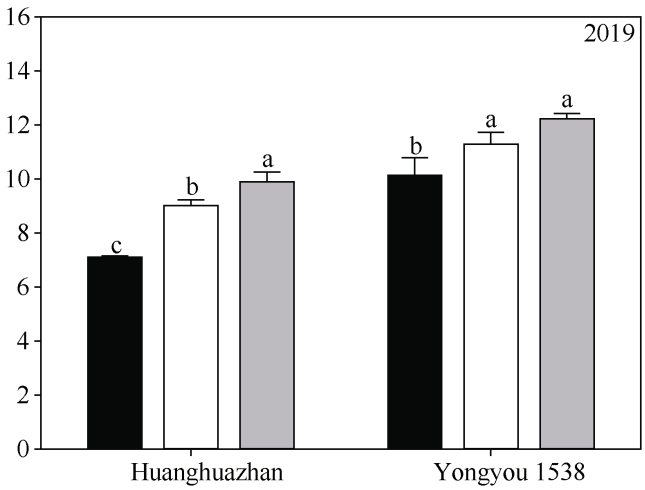

图 1 黄华占和甬优 1538 在不同种植方式下的产量

Fig. 1 Grain yield of Huanghuazhan and Yongyou 1538 under different rice establishment methods

不同小写字母代表同一年份下同一品种在不同种植方式间的多重比较(LSD 测验 $5 \%$ 水平)。

Different lowercase letters denote the variances of different establishment methods of the same variety in a year ( $5 \%$ level according to LSD test).

表 3 黄华占和角优 1538 在不同种植方式下的产量构成因子

Table 3 Yield components of Huanghuazhan and Yongyou 1538 under different rice establishment methods

\begin{tabular}{|c|c|c|c|c|c|c|c|}
\hline $\begin{array}{l}\text { 年份 } \\
\text { Year }\end{array}$ & $\begin{array}{c}\text { 品种 } \\
\text { Variety }\end{array}$ & & $\begin{array}{c}\text { 种植方式 } \\
\text { Establishment methods }\end{array}$ & $\begin{array}{c}\text { 单位面积有效穗数 } \\
\text { Panicle numbers } \\
\text { per } \mathrm{m}^{2}\end{array}$ & $\begin{array}{c}\text { 每穗粒数 } \\
\text { Spikelets per } \\
\text { panicle } \\
\end{array}$ & $\begin{array}{c}\text { 结实率 } \\
\text { Seed setting } \\
\text { rate }(\%)\end{array}$ & $\begin{array}{c}\text { 千粒重 } \\
\text { 1000-grain } \\
\text { weight (g) }\end{array}$ \\
\hline \multirow[t]{8}{*}{2018} & 黄华占 & 手插秧 & Manual transplanting & $254.7 \mathrm{~b}$ & $164.0 \mathrm{a}$ & $88.3 \mathrm{a}$ & $19.4 \mathrm{a}$ \\
\hline & Huanghuazhan & 手抛秧 & Manual seedling-broadcasting & $340.0 \mathrm{a}$ & $156.6 \mathrm{a}$ & $85.6 \mathrm{a}$ & $19.7 \mathrm{a}$ \\
\hline & & 机抛秧 & Mechanical seedling-broadcasting & $308.0 \mathrm{a}$ & $158.7 \mathrm{a}$ & $88.5 \mathrm{a}$ & $19.4 \mathrm{a}$ \\
\hline & & 平均值 & Mean value & $300.9 \mathrm{~A}$ & $159.8 \mathrm{~A}$ & $87.5 \mathrm{~A}$ & $19.5 \mathrm{~A}$ \\
\hline & 角优 1538 & 手插秧 & Manual transplanting & $190.7 \mathrm{~b}$ & $320.6 \mathrm{a}$ & $70.5 \mathrm{~b}$ & $20.0 \mathrm{a}$ \\
\hline & Yongyou 1538 & 手抛秧 & Manual seedling-broadcasting & $310.7 \mathrm{a}$ & $312.7 \mathrm{a}$ & $76.3 \mathrm{ab}$ & $20.7 \mathrm{a}$ \\
\hline & & 机抛秧 & Mechanical seedling-broadcasting & $313.3 \mathrm{a}$ & $307.7 \mathrm{a}$ & $79.7 \mathrm{a}$ & $20.3 \mathrm{a}$ \\
\hline & & 平均值 & Mean value & $271.6 \mathrm{~A}$ & $313.7 \mathrm{~A}$ & $77.6 \mathrm{~A}$ & $20.9 \mathrm{~A}$ \\
\hline \multirow[t]{8}{*}{2019} & 黄华占 & 手插秧 & Manual transplanting & $282.7 \mathrm{~b}$ & $170.0 \mathrm{a}$ & $78.4 \mathrm{~b}$ & $18.1 \mathrm{a}$ \\
\hline & Huanghuazhan & 手抛秧 & Manual seedling-broadcasting & $372.0 \mathrm{a}$ & $146.8 \mathrm{~b}$ & $79.3 \mathrm{ab}$ & $18.9 \mathrm{a}$ \\
\hline & & 机抛秧 & Mechanical seedling-broadcasting & $377.3 \mathrm{a}$ & $151.7 \mathrm{ab}$ & $83.4 \mathrm{a}$ & $19.1 \mathrm{a}$ \\
\hline & & 平均值 & Mean value & $344.0 \mathrm{~A}$ & $156.2 \mathrm{~A}$ & $80.4 \mathrm{~B}$ & $18.7 \mathrm{~A}$ \\
\hline & 角优 1538 & 手插秧 & Manual transplanting & $193.3 \mathrm{~b}$ & $303.4 \mathrm{a}$ & $76.2 \mathrm{~b}$ & $21.1 \mathrm{a}$ \\
\hline & Yongyou 1538 & 手抛秧 & Manual seedling-broadcasting & $289.3 \mathrm{a}$ & $261.6 \mathrm{~b}$ & $76.3 \mathrm{~b}$ & $20.9 \mathrm{a}$ \\
\hline & & 机抛秧 & Mechanical seedling-broadcasting & $286.7 \mathrm{a}$ & $263.9 \mathrm{~b}$ & $80.4 \mathrm{a}$ & 20.9 a \\
\hline & & 平均值 & Mean value & $256.4 \mathrm{~A}$ & $276.3 \mathrm{~A}$ & $75.5 \mathrm{~A}$ & $20.3 \mathrm{~A}$ \\
\hline
\end{tabular}


加 $20.9 \%$ 64.2\%，这可能是其增产的主要原因。另一 方面，与手抛秧相比，精量有序机抛秧的结实率增 加了 $3 \sim 5$ 个百分点, 但单位面积有效穗数、每穗粒 数和千粒重未出现显著性差异, 这在 2 个品种和 2 年间均呈现一致规律。

\section{3 分蒏动态}

不同种植方式下的分葲发生特性存在明显差异 (图 2)。与手抛秩和精量有序机抛相比, 手插秧的分 葟速度和最终分啋数明显降低, 这可能是其单位面 积有效穗数降低的主要原因。2 种抛秧模式的分藍 发生动态亦存在一定差异，与手抛积相比，精量有 序机抛种在生长前期分菜发生较慢, 而随着水稻群 体的进一步生长, 其分藍速度逐步增加, 其最终分 菜数与手抛种基本无明显差异(2019 年角优 1538 除 外，其机抛秩分萻数明显低于手抛秩)。

\section{4 干物质积累}

不同种植方式在不同生育时期的地上部干物质 积累量如图 3 所示, 分臨中期各种植方式下的地上 部生物量无显著性差异, 随着植株进一步生长, 精 量有序机抛秩在幼穗分化期、齐穗期和成熟期的地 上部干物质积累量均显著大于手插秩。同时，精量

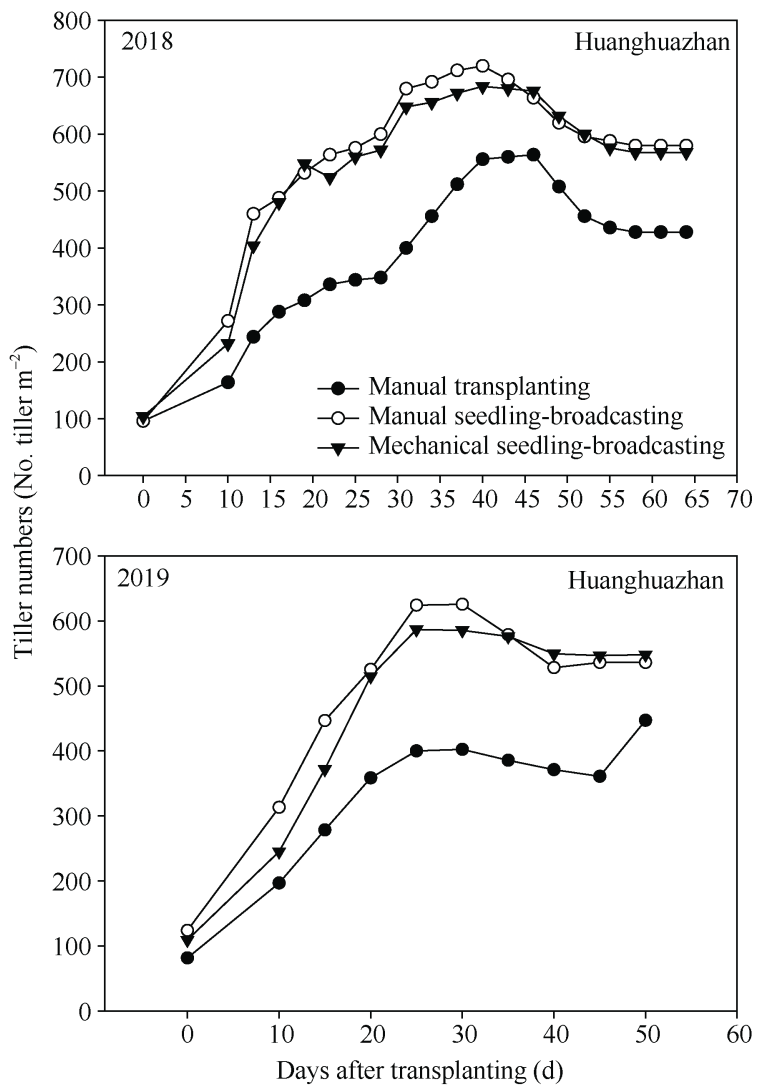

有序机抛秧的地上部生物量在幼穗分化期和齐穗期 小于手抛种或无显著性差异，而在成熟期，精量有 序抛秩和手抛秩的地上部生物量差异不显著。

分析不同种植方式下的花后干物质积累量发现, 精量有序机抛模式下的花后干物质积累量较大，较 手插秧和手拋秧分别增加 52.8\%和 23.4\% (图 4), 这 在不同年份和品种间均呈现一致规律。而手抛秩和 手插秧的花后干物质积累量存在年际差异。2018 年 黄华占和甬优 1538 的花后干物质积累量均表现为手 抛秩大于手插秩, 而 2019 年 2 种种植方式间无显著 性差异。

\section{5 叶片 SPAD 值}

不同种植方式在不同生育时期的叶片 SPAD 值 如图 5 所示, 精量有序机抛秧的 SPAD 值在分藍中 期、幼穗分化期、齐穗期均大于手插种和手抛秩模 式，而在齐穗后 $10 \mathrm{~d}$ ，精量有序机抛秧叶片 SPAD 值 的下降程度要小于其他 2 种模式, 这在 2 个品种间 均呈现一致规律, 表明其叶片衰老速率可能较慢。 另一方面，黄华占在手抛积模式下的叶片 SPAD 值 与手插秧无显著性差异, 但在甬优 1538 中, 手抛种 的叶片 SPAD 值在各生育时期均显著大于手插秩。
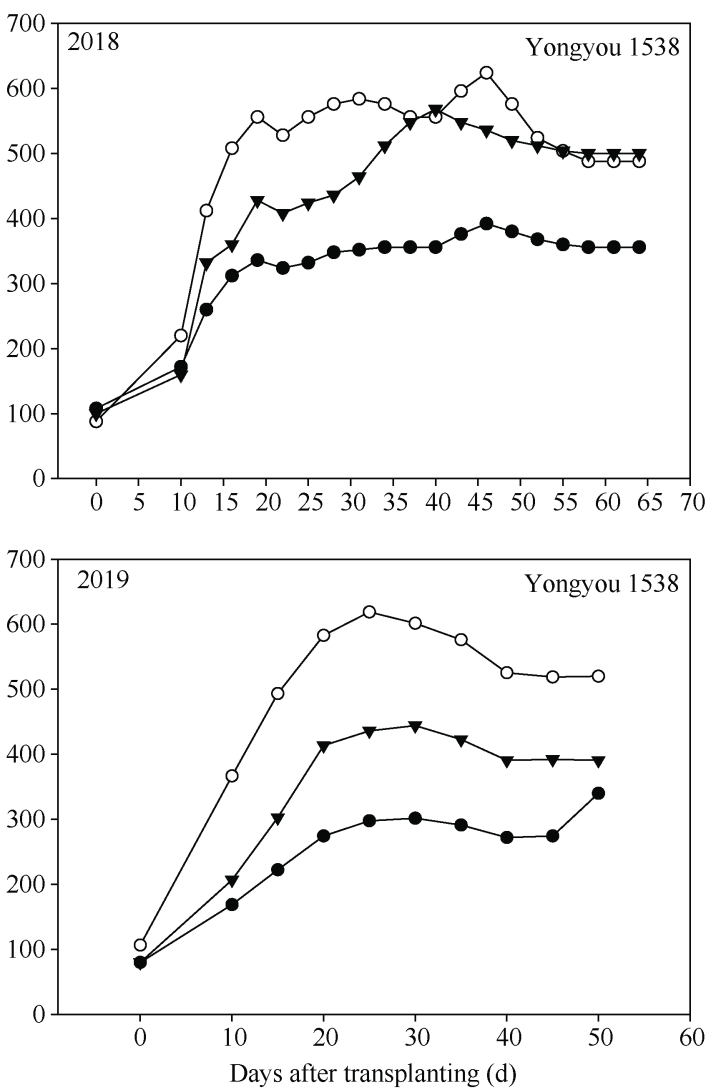

图 2 黄华占和甬优 1538 在不同种植方式下的分藍动态

Fig. 2 Tillering dynamics of Huanghuazhan and Yongyou 1538 under different rice establishment methods 

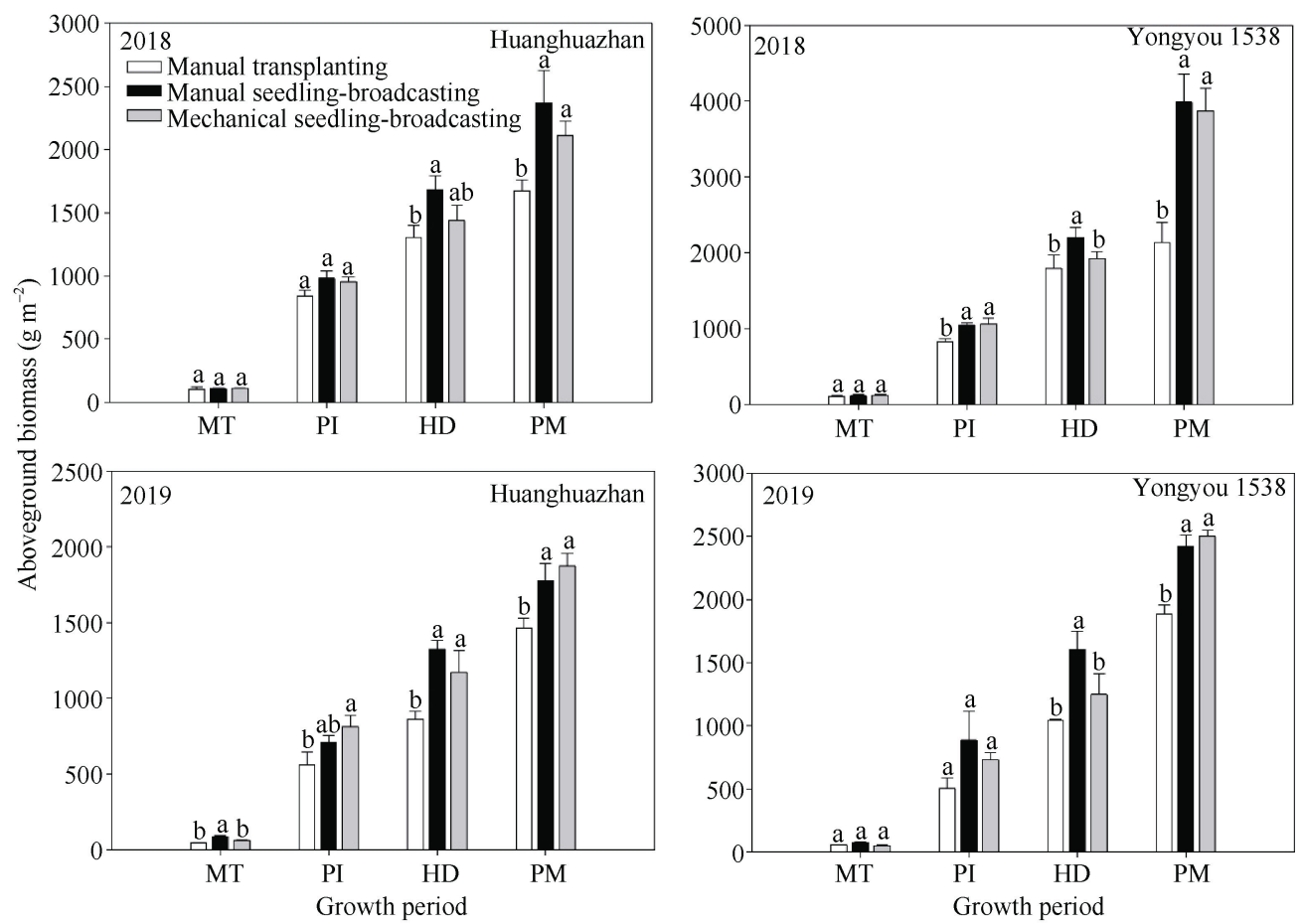

图 3 黄华占和甬优 1538 在不同种植方式下的地上部生物量

Fig. 3 Above-ground biomass of Huanghuazhan and Yongyou 1538 under different rice establishment methods

MT: 分葟中期; PI: 幼穗分化始期; HD：抽穗期; PM：成熟期。每张副图中，不同小写字母代表不同种植方式在同一生育时期的多重比 较( LSD 测验 $5 \%$ 水平)。

MT: middle tillering; PI: Panicle initation; HD: heading; PM: physiological maturity. In each sub-figure, different lowercase letters denote the variances between different establishment methods at the same growth period ( $5 \%$ level according to LSD test).
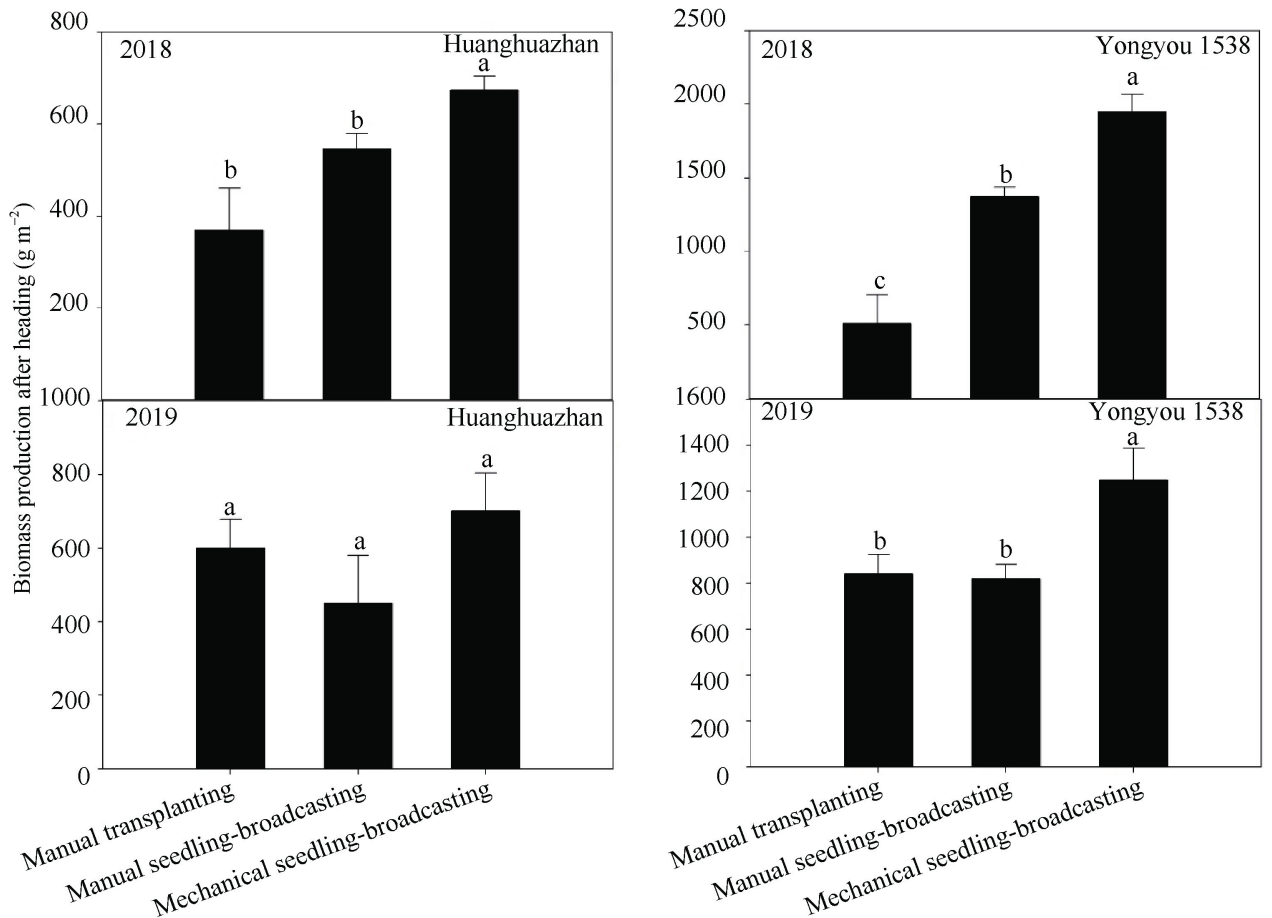

图 4 黄华占和甬优 1538 在不同种植方式下的花后干物质积累量

Fig. 4 Dry matter accumulation of Huanghuazhan and Yongyou 1538 at post-flowering stage under different rice establishment methods

不同小写字母代表不同种植方式在 5\%差异显著水平上的多重比较(LSD 测验)。

Different lowercase letters denote the variances between different establishment methods at the 5\% probability level according to LSD test. 

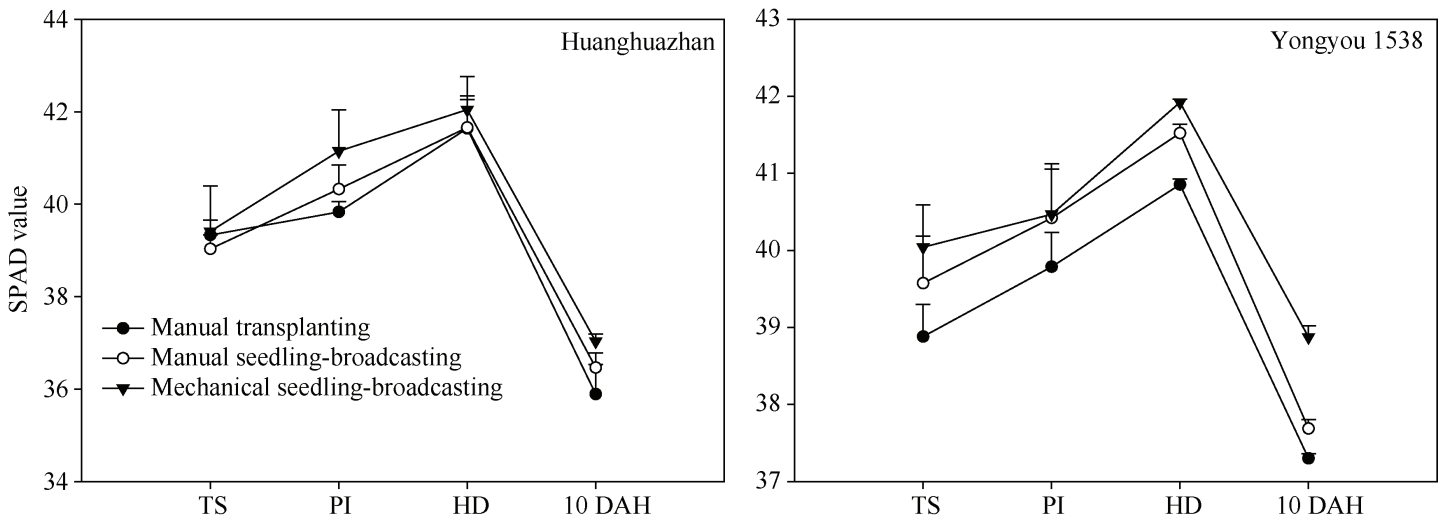

图 5 黄华占和甬优 1538 在不同种植方式下的 SPAD 值变化特征

Fig. 5 SPAD values of Huanghuazhan and Yongyou 1538 under different rice establishment methods

TS: 分藮中期; PI：幼穗分化始期; HD：抽穗期; $10 \mathrm{DAH}$ ：抽穗后 $10 \mathrm{~d}$ 。

TS: middle tillering; PI: panicle initation; HD: heading; $10 \mathrm{DAH}: 10$ days after heading.

\section{6 田间通风性}

为比较不同种植模式的田间通风性差异, 本研 究于 2019 年在各品种齐穗期对水稻群体的田间风 速和阵风速度进行了测定(图 6)。研究结果发现, 精 量有序机抛秧群体的田间风速和阵风速度明显大于 手抛秧群体，表明其在生育后期的田间通风性能优 于手抛秩。但是, 精量有序机抛秧的田间风速和阵 风速度低于手插秩。角优 1538 和黄华占在不同种植 方式下的通风性能表现均呈现一致规律。

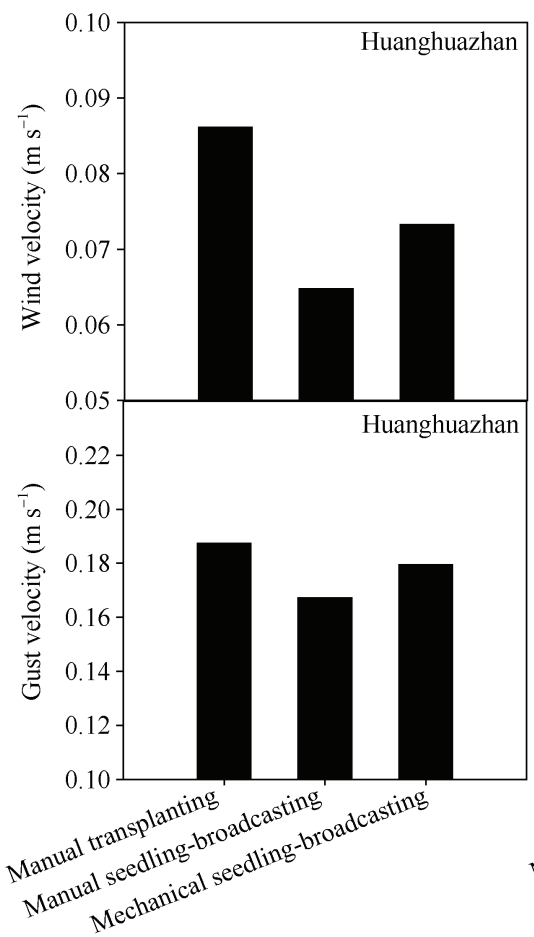

\section{3 讨论}

本研究结果表明, 精量有序机抛秧的产量在不 同年份和不同品种间均显著高于手插秩，且 2018 年 在甬优 1538 和 2019 年在 2 个品种中的产量均高于 手抛秩，产量优势明显。表明精量有序机抛秧是一 种高产的水稻种植方式，有较大的推广潜力和价值。

分析不同种植方式下水稻的产量构成和生长特 性发现，精量有序机抛秧模式前期生长快，分蒠数 量多，群体生物量大，使得成熟期单位面积有效穗

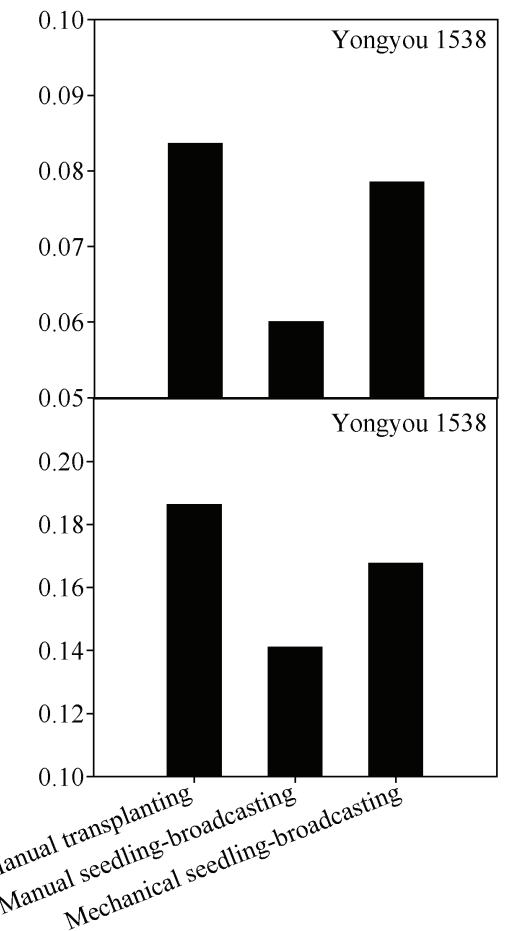

图 6 黄华占和甬优 1538 在不同种植方式下的风速和阵风速度

Fig. 6 Wind and gust velocity of Huanghuazhan and Yongyou 1538 under different rice establishment methods 
数较手插秧模式显著提升。前人围绕抛秩稻的生长 发育特性的研究也与本文结果基本一致 ${ }^{[3,15]}$ 。人工撒 抛积和精量有序机抛秧在栽插过程和群体田间分布 等方面均存在较大差别，进而可能导致生长发育特 性和产量形成等方面的差异。前人研究指出撒抛秩 苗根系入土较浅，部分根系裸露在土表，导致下部 叶片易死亡，种苗素质差 ${ }^{[16-18]}$ 。而有序抛栽(点抛或 摆秩)秩苗垂直入土、根系下扎深，立苗返青快 ${ }^{[19]}$ 。

同时，有序抛栽分蔾发生叶位比手抛秧低 2 个叶位,

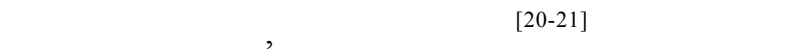
现, 精量有序机抛秧前期分辠能力和群体生长速率 基本弱于手抛秩, 与前人研究结果存在一定差异, 这可能是因为机抛种作业过程中对秧苗存在机械损 伤，进而影响群体缓青及发苗速度。同时，机抛秩移 栽对大田耕整和水层深度要求更高, 若土表较硬或 水层较深, 可能导致机抛秧立苗困难 ${ }^{[14]}$ 。在生育中 期, 精量有序机抛种的分菩速度加快, 移栽后 45 50 d 与手抛秧分竪数相当 (2019 年甬优 1538 除外), 这可 能是精量有序机抛秧群体田间分布均匀, 通风透光 良好，进而有利于群体生长。分析产量构成因子发 现，精量有序机抛秧的单位面积有效穗数和每穗粒 数与手抛秩无显著性差异。而前人研究结果认为有 序抛栽的有效穗数小于手工抛栽, 但每穗粒数呈现 相反趋势 ${ }^{[17,22]}$ 。综上所述, 本研究中精量有序机抛种 在前期生长、分葲发生和单位面积总颖花数等方面 较手抛秩未表现出明显优势, 未来研究需通过抛秧 机械改进、育秧和抛栽配套技术的优化等来充分挖 掘精量有序机抛秧前期生长优势。同时, 精量有序 机抛秧模式下的立苗缓青过程、秧苗素质和分葟发 生特性等还需要进一步深入研究。

本研究发现, 精量有序机抛秧的结实率优于手 抛秩，同时其花后干物质积累量大，叶片 SPAD 值 在生育后期衰减较慢, 表明与手抛种相比, 精量有 序机抛秩高产的主要原因可能是生育后期较强的光 合同化能力和较高的库充实度。进一步研究发现, 精量有序机抛秧群体田间通风条件优于手抛秩，而 前人围绕有序抛种(手工点拋)的研究指出也点抛群 体分布均匀, 使田间通风透光条件得以改善, 光合 作用和光合势增强 ${ }^{[23]}$, 这种后期生长势为大库提供 了足源, 为抛积群体高产潜力得以充分发挥奠定了 基础 ${ }^{[16,19]}$ 。此外, 精量有序机抛秧后期光合同化能力 强、叶片衰老慢的特性可能还得益于较高的根系活
力。郭保卫等研究指出, 和撒抛秧相比, 有序摆栽和 半有序点抛均可显著提升水稻群体各生育时期的群 体根干质量、根冠比和根系活力, 同时耕作底层根 量大于撒抛 ${ }^{[24]}$ 。然而本研究中, 精量有序机抛秧模 式的根层分布特征和根系生长特性还不清晰, 其 根系生长规律与高产形成的联系还需深入研究来 揭示。

\section{4 结论}

精量有序机抛秧是一种高产的水稻种植方式, 其产量较手插秩平均增加 $22.4 \%$ 28.3\%, 较手抛种 增加 $2.8 \%$ 8.9\%。生长发育特性方面, 精量有序机抛 秩田间分布有序，田间通风性好，群体生育后期的 干物质同化积累能力强，叶片衰老较慢、库充实度 高, 与手插秩相比, 其单位面积有效穗数显著提升, 与手抛秧相比, 其结实率明显增加, 进而促进其高 产。然而, 精量有序机抛秧模式下抛秧机和配套育 秩栽插技术等方面还有待改进以进一步发挥高产潜 能。同时，未来研究还需围绕精量有序机抛种技术 的立苗缓青特征、分葟发生特性和根系生长特点等 方面深入开展。

\section{References}

[1] 金千瑜. 我国水稻抛种栽培技术的应用与发展. 中国稻米, 1996, (1): 10-13.

Jin Q Y. The application and development of rice seedling broadcasting in China. China Rice, 1996, (1): 10-13 (in Chinese with English abstract).

[2] 陈健. 水稻栽培方式的演变与发展研究. 沈阳农业大学学报, 2003, 34: 389-393.

Chen J. Evolution and development of rice planting pattern. $J$ Shenyang Agric Univ, 2003, 34: 389-393 (in Chinese with English abstract).

[3] 张洪程, 戴其根, 霍中洋, 许轲, 魏海燕. 中国抛积稻作技术 体系及其特征. 中国农业科学, 2008, 41: 43-52.

Zhang H C, Dai Q G, Huo Z Y, Xu K, Wei H Y. Cultivation technical system of rice seedling broadcasting and its characteristics. Sci Agric Sin, 2008, 41: 43-52 (in Chinese with English abstract).

[4] 胡雅杰, 张洪程, 龚金龙, 龙厚元, 戴其根, 霍中洋, 许轫, 魏 海燕, 李德剑, 沙安勤, 周有炎, 罗学超, 刘国林, 赵德亮. 不 同栽培方式对水稻产量和物质生产特征影响. 中国稻米, 2012, 18(5): 15-19.

Hu Y J, Zhang H C, Gong J L, Long H Y, Dai Q G, Huo Z Y, Xu K, Wei H Y, Li D Y, Sha A Q, Zhou Y Y, Luo X C, Liu G L, Zhao D L. Effects of cultivation methods on the grain yield and biomass production characteristics of rice. China Rice, 2012, 18(5): 15-19 (in Chinese with English abstract).

[5] 戴其根, 霍中洋, 张洪程, 苏宝林, 许轫, 丘枫. 抛秩水稻生 长发育与产量形成的生态生理机制 II 秧苗田间垂直分布格局 
及其生态生理效应. 作物学报, 2001, 27: 600-611.

Dai Q G, Huo Z Y, Zhang H C, Su B L, Xu K, Qiu F. The eco-physiological mechanism of growth, development and yield formation of broadcasted rice seedlings, the characteristics of II spatial distribution of plant on perpendicular and its eco-physiological effect. Acta Agron Sin, 2001, 27: 600-611 (in Chinese with English abstract).

[6] 戴其根, 张洪程, 霍中洋, 许轫, 丘枫. 抛种稻生长发育特征 及产量形成规律的探讨. 江苏农业研究, 2000, 21(1): 1-7.

Dai Q G, Zhang H C, Huo Z Y, Xu K, Qiu F. Characteristics of growth and yield formation of broadcasting-seedling of rice. Jiangsu Agric Res, 2000, 21(1): 1-7 (in Chinese with English Abstract).

[7] 间凤宇, 于凤阁. 水稻抛种应用现状及技术要点. 现代农业科 技, 2011, (3): 99-101.

Yan F Y, Yu F G. The application status and technical essentials for rice seedling broadcasting. Adv Agric Technol, 2011, (3): 99-101 (in Chinese with English abstract).

[8] 孙永健, 徐徽, 秦俭, 贾现文, 马均. 栽培方式与免耕对杂交 稻II 优 498 灌浆期根系衰老和籽粒灌浆的影响. 中国农业科学, 2013, 46: 1347-1358.

Sun Y J, Xu H, Qin J, Jia X W, Ma J. Influence of cultivation methods and no-tillage on root senescence at filling stage and grain-filling properties of II you 498. Sci Agric Sin, 2013, 46: 1347-1358 (in Chinese with English abstract).

[9] 罗锡文, 王在满. 水稻生产全程机械化技术研究进展. 现代农 业装备, 2014, (1): 23-29.

Luo X W, Wang Z M. Research progress of rice production mechanization technology. Mod Agric Equip, 2014, (1): 23-29 (in Chinese with English abstract).

[10] 夏倩倩, 张文毅, 纪要, 李坤. 我国机械抛秧技术与装备的研 究现状及趋势. 中国农机化学报, 2019, 40(6): 201-208.

Xia Q Q, Zhang W Y, Ji Y, Li K. Research status and trend of mechanical throwing seedling technology and equipment in China. J Chin Agric Mechan, 2019, 40(6): 201-208 (in Chinese with English abstract).

[11] 谭艳红. 水稻抛秧机关键部件机构设计与试验研究. 湖南农 业大学硕士学位论文, 湖南长沙, 2016.

Tan Y H. Design and Experimental Research of Key Components on Rice Throwing Machine. MS Thesis of Hunan Agricultural University, Changsha, Hunan, China, 2016 (in Chinese with English abstract).

[12] 陈旭暄, 宋建农, 刘建军, 魏青. 水稻钵苗输秧拔秧机构参数 优化. 中国农业大学学报, 2005, 10(2): 19-21.

Chen X X, Song J N, Liu J J, Wei Q. Parametric optimization of a transporting and evulsing mechanism of potted rice seedlings. $J$ China Agric Univ, 2005, 10(2): 19-21 (in Chinese with English abstract).

[13] 王国强. 浅析 2ZU-6 型播秧机性能与推广. 农业装备技术, 2002, (1): 17-18.

Wang G Q. The extension and evaluation of 2ZU-6 rice transplanting machine. Technol Agric Equip, 2002, (1): 17-18 (in Chinese).

[14] 汪友祥, 彭洪巽. 2ZP-13 型水稻有序抛种机的研发与推广. 农 业机械, 2018, (11): 87-90.

Wang Y X, Peng H X. The development and extension of 2ZP-13 orderly rice throw-transplanting machine. Agric Machine, 2018, (11): 17-18 (in Chinese).

[15] 张洪程, 戴其根, 丘枫, 霍中洋, 许轫, 董明辉, 杨海生. 抛种 稻产量形成的生物学优势及高产栽培途径的研究. 江苏农学 院学报, 1998, 19(3): 11-17.

Zhang H C, Dai Q G, Qiu F, Huo Z Y, Xu K, Dong M H, Yang H S. Studies on the biological superiority of yield formation of broadcasting-seedling rice and its high-yielding cultured way. $J$ Jiangsu Agric Coll, 1998, 19(3): 11-17 (in Chinese with English abstract).

[16] 郭保卫, 陈厚存, 张春华, 魏海燕, 张洪程, 戴其根, 霍中洋, 许轫, 邢琳, 管文文, 黄幸福, 杨雄. 水稻抛栽秧苗立苗中的 形态与生理变化. 作物学报, 2010, 36: 1715-1724.

Guo B W, Chen H C, Zhang C H, Wei H Y, Zhang H C, Dai Q G, Huo Z Y, Xu K, Xing L, Guan W W, Huang X F, Yang X. Morphological and physiological changes in seedling standing and establishment of broadcasted rice seedlings. Acta Agron Sin, 2010, 36: 1715-1724 (in Chinese with English abstract).

[17] 张洪程, 朱聪聪, 霍中洋, 许轫, 蒋晓鸿, 陈厚存, 高尚勤, 李 德剑, 赵成美, 戴其根, 魏海燕, 郭保卫. 钵苗机插水稻产量 形成优势及主要生理生态特点. 农业工程学报, 2013, 29(21): $50-59$.

Zhang H C, Zhu C C, Huo Z Y, Xu K, Jiang X H, Chen H C, Gao S Q, Li D J, Zhao C M, Dai Q G, Wei H Y, Guo B W. Advantages of yield formation and main characteristics of physiological and ecological in rice with nutrition bowl mechanical transplanting. Trans CSAE, 2013, 29(21): 50-59 (in Chinese with English abstract).

[18] 于否, 牟雪雷, 韩休海, 沈亮. 水稻钵育摆栽技术的应用及发 展. 农机化研究, 2011, 33(9): 212-215.

Yu L, Mou X L, Han X H, Shen L. The application and development of rice bowl-seedling transplanting technology. J Agric Mechan Res, 2011, 33(9): 212-215 (in Chinese with English abstract).

[19] 郭保卫. 水稻有序摆栽超高产形成及其生理生态特征的研究. 扬州大学博士学位论文, 江苏扬州, 2013.

Guo B W. Studied on Super High Yield Formation and Its Eco-Physiological Characteristics of Ordered Transplanting and Optimized Broadcasting Rice. PhD Dissertation of Yangzhou University, Yangzhou, Jiangsu, China, 2013 (in Chinese with English abstract).

[20] 刘华招, 王春江. 不同移栽方式对秧苗返青分䅦的影响. 现代 化农业, 2006, (10): 15-16.

Liu H Z, Wang C J. The effects of transplanting methods on the recovery and tillering ability of rice seedlings. Mod Agric, 2006, (10): 15-16 (in Chinese with English abstract).

[21] 江立庚, 徐世宏, 李如平, 何礼健, 陈德威, 秦华东, 杨为芳, 谭素宁, 陈明才, 郑希, 陆福勇, 唐茂艳. 稻田耕作方式对抛 积稻分菅特性的影响. 杂交水稻, 2006, (增刊 1): 23-25.

Jiang L G, Xu S H, Li R P, He L J, Chen D W, Qin H D, Yang W F, Tan S N, Chen M C, Zheng X, Lu F Y, Tang M Y. effects of tillage methods on the tillering ability of seedling-broadcasting rice. Hybrid Rice, 2006, (S1): 23-25 (in Chinese with English abstract).

[22] 陈国建. 水稻针育摆栽高产稳产机理分析. 星殖与稻作, 2004, (5): 28-30. 
Chen G J. High yielding mechanisms of rice with nutrition bowl mechanical transplanting. Reclaim Rice Cult, 2004, (5): 28-30 (in Chinese with English abstract).

[23] 林贤青, 周伟军, 朱德峰, 张玉屏, 杨国花. 强化栽培下水稻 穗分化期叶片光合速率与水分利用率的研究. 中国水稻科学, 2005, 19: 132-136.

Lin X Q, Zhou W J, Zhu D F, Zhang Y P, Yang G H. Photosynthetic rate and water use efficiency of leaves at different positions during panicle initiation stage under the system of rice intensification. Chin J Rice Sci, 2005, 19: 132-136 (in Chinese with
English abstract).

[24] 郭保卫, 许轫, 张洪程, 戴其根, 霍中洋, 魏海燕, 陈厚存. 有 序摆抛栽超高产栽培对水稻根系形态生理特征的影响. 中国 水稻科学, 2016, 30: 611-625.

Guo B W, Xu K, Zhang H C, Dai Q G, Huo Z Y, Wei H Y, Chen H C. Effects of ordered transplanting and optimized broadcasting on rice root system morphological and physiological characteristics under super high-yielding cultivation. Chin J Rice Sci, 2016, 30: 611-625 (in Chinese with English abstract). 